\title{
Fine-scale in-situ measurement of lead ions in coastal sediment pore water based on an all-solid-state potentiometric microsensor
}

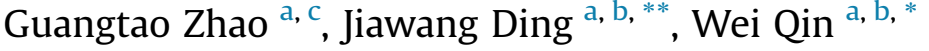 \\ ${ }^{a}$ Key Laboratory of Coastal Environmental Processes and Ecological Remediation, Yantai Institute of Coastal Zone Research (YIC), Chinese Academy of \\ Sciences(CAS), Shandong Key Laboratory of Coastal Environmental Processes, YICCAS, Yantai, Shandong, 264003, China \\ ${ }^{\mathrm{b}}$ Laboratory for Marine Biology and Biotechnology, Qingdao National Laboratory for Marine Science and Technology, Qingdao, China \\ ' University of Chinese Academy of Sciences, Beijing, 100049, China
}

\section{H I G H L I G H T S}

- An all-solid-state lead-selective microelectrode is described for pore water analysis.

- The microsensor allows the direct measurement of $\mathrm{Pb}^{2+}$ in a coastal sediment core.

- In-situ measurements of the vertical profiles of $\mathrm{Pb}^{2+}$ in pore water is achieved.

\section{A R T I C L E I N F O}

\section{Article history:}

Received 2 February 2019

Received in revised form 29 March 2019

Accepted 25 April 2019

Available online 26 April 2019

\section{Keywords:}

Lead-selective microelectrode

Fine-scale

In-situ measurement

Coastal sediment

Pore water
G R A P H I C A L A B S T R A C T

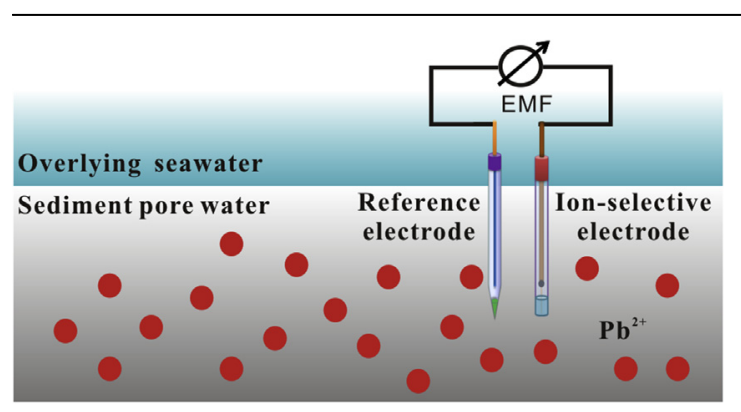

\begin{abstract}
A B S T R A C T
Methods for in-situ measurements of heavy metal ions in coastal sediment pore water to elucidate finescale biogeochemical and environmental processes are highly required but have rarely been reported. In this work, an all-solid-state lead-selective microelectrode $\left(\mathrm{Pb}^{2+}-\mathrm{IS} \mu \mathrm{E}\right)$ based on a poly $(3,4-$ ethylenedioxythiophene)-poly(sodium 4-styrenesulfonate) (PEDOT/PSS) modified gold wire with a diameter of $14 \mu \mathrm{m}$ has been fabricated. The proposed $\mathrm{Pb}^{2+}-\mathrm{IS} \mu \mathrm{E}$ is capable of in-situ measurement of $\mathrm{Pb}^{2+}$ in coastal sediment pore water at millimeter depth intervals. The $\mathrm{Pb}^{2+}-\mathrm{IS} \mu \mathrm{E}$ shows a Nernstian response for $\mathrm{Pb}^{2+}$ within the activity range of $2.1 \times 10^{-9}-2.1 \times 10^{-4} \mathrm{M}\left(\mathrm{S}=28.1 \pm 1.3 \mathrm{mV} / \mathrm{dec}, \mathrm{R}^{2}=0.998\right)$ in $0.5 \mathrm{M}$ $\mathrm{NaCl}$, and the detection limit is $6.4 \times 10^{-10} \mathrm{M}$. By lowering the microelectrode into a coastal sediment core with a micro-manipulator, the proposed $\mathrm{Pb}^{2+}-\mathrm{IS} \mu \mathrm{E}$ allows the direct measurement of the vertical distribution profile of $\mathrm{Pb}^{2+}$ in the pore water. The in-situ measurement of $\mathrm{Pb}^{2+}$ using the microsensor could avoid the problems of sample handling. Moreover, the detection system can be extended to assess the vertical distribution profiles of other heavy metal ions in sediment pore water by using different ionselective microelectrodes.
\end{abstract}

(c) 2019 Elsevier B.V. All rights reserved.

\footnotetext{
* Corresponding author. Key Laboratory of Coastal Environmental Processes and Ecological Remediation, Yantai Institute of Coastal Zone Research (YIC), Chinese Academy of Sciences(CAS), Shandong Key Laboratory of Coastal Environmental Processes, YICCAS, Yantai, Shandong, 264003, China.

** Corresponding author. Key Laboratory of Coastal Environmental Processes and Ecological Remediation, Yantai Institute of Coastal Zone Research (YIC), Chinese Academy of Sciences(CAS), Shandong Key Laboratory of Coastal Environmental Processes, YICCAS, Yantai, Shandong, 264003, China.

E-mail addresses: jwding@yic.ac.cn (J. Ding), wqin@yic.ac.cn (W. Qin).
} 


\section{Introduction}

Coastal sediments would have large amounts of heavy metals due to the transportation through rivers [1,2] and the trapping effect of particles [3]. Pore water is the intermediate medium for the exchange of heavy metals between sediments and overlying water layers [4]. The release of heavy metals from the sediments into the pore water would cause a secondary pollution under a change of the environmental conditions [5]. Therefore, the accurate, rapid and direct determination of heavy metal ions in coastal sediment pore water is of great significance for evaluation of their impacts on water quality and ecological environment.

Pore water analysis has been commonly performed by combination of sample extraction via centrifugation of the bulk sediment, or via squeezing the sediment core with subsequent laboratory tests [6]. In recent years, techniques based on diffusive equilibrium in thin films (DET) and diffusive gradients in thin films (DGT) have been widely used for detecting total dissolved and labile trace metals in the sediment pore water with high resolutions [7]. However, extensive sample preparation procedures may destroy/ disturb the sediment samples and change the microenvironment of the sediment pore water [8]. Therefore, in-situ measurements without sampling processes are still highly required. Moreover, the microscale structures and the rapidly changing conditions of pore water require methods that enable high-resolution spatial investigations.

Electrochemical methods have been widely used in measurements of trace heavy metals with the attractive features of high sensitivity, low cost and sufficient accuracy. Pore water profiles of $\mathrm{Mn}$, and Fe at (sub)millimeter resolution could be measured by using voltammetric microelectrodes [9]. Gel integrated single microelectrodes or gel integrated microelectrodes arrays combined to voltammetric in-situ profiling system have been applied for the detection of heavy metals in natural waters and other complex media $[10,11]$. However, dissolved oxygen could induce a serious interference for in-situ measurements of heavy metals in pore water [12]. Microsensors based on polymeric membrane ionselective electrodes (ISEs), with attractive features such as fast response time, low detection limit, and broad dynamic response range, show promising applications in pore water analysis and could resolve the spacial profiles at fine scales. Since the ISEs with low detection limits were reported in 1997 [13], the development and applications of potentiometric microsensors have made great progress. Most of the potentiometric sensors are liquid-filled microelectrodes with glass capillaries $[14,15]$. These potentiometric microelectrodes were used to monitor ion concentrations in various fields, including biological analysis [16,17], environmental monitoring [18-20], and corrosion process investigation [21]. However, their applications for pore water analysis are rather difficult because of the disadvantages of fragility, short lifetime and low sensitivity. In recent years, all-solid-state potentiometric microelectrodes have been developed with good stability and high sensitivity [22-24]. However, direct measurement of heavy metal ions in coastal sediment pore water by using the all-solid-state potentiometric microsensors has not been reported. Herein, an all-solid-state ion-selective microelectrode (IS $\mu \mathrm{E})$ with a low detection limit is proposed for in-situ measurements of heavy metal ions in sediment pore water. Lead, as one of the well-known highly toxic heavy metals, which poses a serious threat to the environmental ecosystem and human health, has been selected as a model. The selectivity, reproducibility and potential stability of the $\mathrm{Pb}^{2+}$ $\mathrm{IS} \mu \mathrm{E}$ have been characterized. The proposed microelectrode has been used for in-situ measurements of pore water profiles of lead ions.

\section{Materials and methods}

\subsection{Chemicals}

The lead ionophore [tert-butylcalix [4]arene-tetrakis(N,Ndimethylthioacetamide)], 2-nitrophenyl octyl ether (o-NPOE), high molecular weight poly(vinyl chloride) (PVC), monomer 3,4ethylenedioxythiophene (EDOT, > 97\%), poly(sodium 4styrenesulfonate) (NaPSS, $\mathrm{MW}=70000)$, and $\mathrm{NaCl}(99.999 \%)$ were purchased from Sigma-Aldrich. The lipophilic cationexchanger sodium tetrakis[3,5-bis(trifluoromethyl) phenyl]borate (NaTFPB) was purchased from Alfa Aesar. Gold wires (99.9\%) with a diameter of $14 \mu \mathrm{m}$ were purchased from Alfa Aesar. The standard seawater samples (NASS-6) were purchased from the National Research Council of Canada. All other chemicals were of analytical reagent grade. Deionized water (18.2 $\mathrm{M} \Omega$ specific resistance) used throughout was obtained with a Pall Cascada laboratory water system.

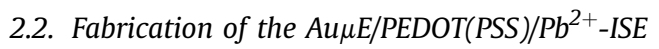

The all-solid-state microelectrodes based on the gold wire electrode $(\mathrm{Au} \mu \mathrm{E})$ with a diameter of $14 \mu \mathrm{m}$ were prepared as described before [23]. The AupE electrodes were modified with PEDOT(PSS) as solid contact through the galvanostatic electrochemical polymerization $[25,26]$. The electrodeposition system consisted of a Pt wire as the counter electrode, an $\mathrm{Ag} / \mathrm{AgCl} / 3 \mathrm{M} \mathrm{KCl}$ microelectrode with a tip diameter of $8-10 \mu \mathrm{m}$ as the reference electrode [27], and the AupEs as the working electrode. The polymerization was carried out in a deaerated solution with 0.1 M EDOT and $0.01 \mathrm{M}$ NaPSS. A constant current of $50 \mathrm{nA}$ was applied for different times to produce polymerization charges from 2 to $7.5 \mu \mathrm{C}$.

After electrodeposition, the Au $\mu$ E/PEDOT(PSS) electrodes were rinsed with deionized water, and then allowed to dry at room temperature. The polymeric membrane composition contained $1.57 \mathrm{wt} \%$ of the lead ionophore, $0.48 \mathrm{wt} \%$ of NaTFPB, $65.30 \mathrm{wt} \%$ of $o-$ NPOE, and $32.65 \mathrm{wt} \%$ of PVC. $200 \mathrm{mg}$ of the membrane components was dissolved in $1.6 \mathrm{~mL}$ of THF. $0.8 \mu \mathrm{L}$ of the lead ion-selective membrane $\left(\mathrm{Pb}^{2+}\right.$-ISM) cocktail solution was applied on the Au $\mu \mathrm{E} /$ PEDOT(PSS), and left to dry overnight. For comparison, the cocktail solution was also applied on the bare $\mathrm{Au} \mu \mathrm{E}$ to prepare the $\mathrm{Au} \mu \mathrm{E} /$ $\mathrm{Pb}^{2+}$-ISE. The prepared $\mathrm{Pb}^{2+}-\mathrm{IS} \mu \mathrm{Es}$ were conditioned in $\mathrm{a}$ $10^{-3} \mathrm{M} \mathrm{Pb}\left(\mathrm{NO}_{3}\right)_{2}$ solution for $2 \mathrm{~h}$ before measurements.

\subsection{Apparatus and measurements}

Potentiometric measurements were performed at room temperature using $\mathrm{CHI} 760 \mathrm{C}$ electrochemical workstation (Shanghai Chenhua Apparatus Corporation, China). The $\mathrm{Pb}^{2+}-\mathrm{IS} \mu \mathrm{E}$ and $\mathrm{Ag} /$ $\mathrm{AgCl} / 3 \mathrm{M} \mathrm{KCl}$ microelectrode were used as indicator and reference electrodes, respectively. The ion activities were calculated by the Debye-Hückel equation [28] and the potentiometric values were corrected for liquid junction potentials according to the Henderson equation [29].

For selectivity measurements, the glassy carbon electrodes (GCE, $3 \mathrm{~mm}$ in diameter) modified with PEDOT(PSS) were used to prepare the GC/PEDOT(PSS)/ $\mathrm{Pb}^{2+}$-ISEs as described before [23]. The GC/PEDOT(PSS)/ $\mathrm{Pb}^{2+}$-ISEs were conditioned in a $10^{-3} \mathrm{M} \mathrm{NaCl}$ solution overnight before potentiometric measurements. Cyclic voltammetry (CV) and electrochemical impedance spectroscopy (EIS) measurements were carried out in a $5 \mathrm{mM} \mathrm{K}_{4}\left[\mathrm{Fe}(\mathrm{CN})_{6}\right] / \mathrm{K}_{3}\left[\mathrm{Fe}(\mathrm{CN})_{6}\right]$ solution containing $0.1 \mathrm{M} \mathrm{KCl}$. 


\subsection{Sample analysis}

In order to investigate the vertical distribution profiles of $\mathrm{Pb}^{2+}$ in coastal sediment pore water, the sediment samples were collected on November 12, $2018\left(37^{\circ} 26^{\prime} \mathrm{N}, 121^{\circ} 34^{\prime} \mathrm{E}\right)$. The $\mathrm{Pb}^{2+}-\mathrm{IS} \mu \mathrm{E}$ and reference microelectrode were mounted onto a MMD-4 micromanipulator (Narishige, Japan) with a distance of $5 \mathrm{~mm}$ (Fig. S1). Electromotive force (EMF) values were measured using a PXSJ-216 Leici pH meter (Shanghai, China). The movements of the two microelectrodes were precisely controlled by the micro-manipulator. The electrode detection system was kept in a Faraday cage to shield external electromagnetic interferences.

Since potentiometry using ion-selective electrodes measures free ion activities in samples, salinity is a potential factor which would influence the performance of the proposed microsensor in real samples. Salinity determines the ion strength of the seawater sample, thus influencing the activity of the free lead ion, which is directly measured by the ion-selective microelectrode. In addition, salinity can change the electrode's potential values due to the change in the liquid junction potential of the reference electrode. For the in-situ analysis, the salinities of the seawaters overlying on the sediments were measured and the EMF values were corrected for the ion strength and liquid junction potential.

\section{Results and discussion}

\subsection{Electrodeposition of the PEDOT(PSS) film}

The bulk redox capacitance of PEDOT(PSS) can be well controlled by the amount of the polymerization charge [30]. As shown in Fig. $1 \mathrm{~A}$, the redox currents of $\mathrm{Fe}(\mathrm{CN})_{6}^{4-} \beta^{3-}$ and the redox capacitances of the electrodes are found to increase with increasing polymerization charge. The values of the redox capacitances for the
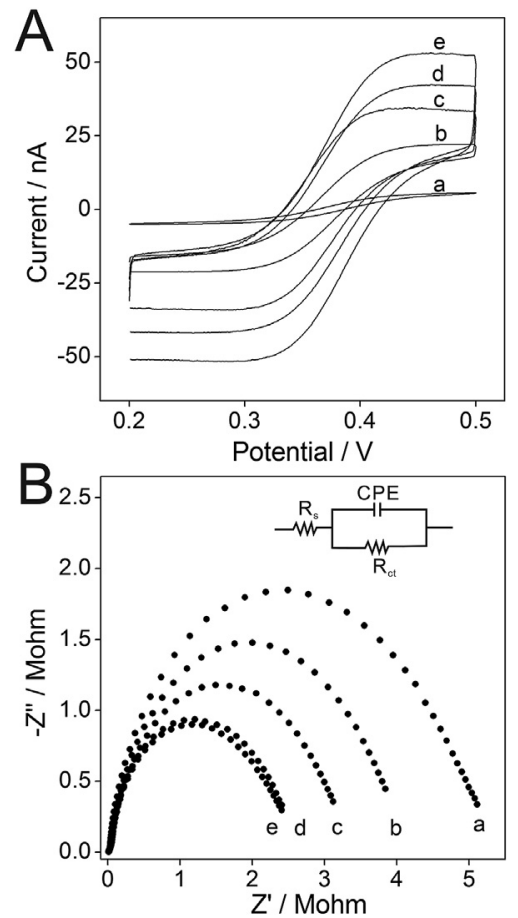

Fig. 1. (A) CVs and (B) EIS of the Au $\mu$ Es in a $\left.5 \mathrm{mM} \mathrm{Fe}(\mathrm{CN})_{6}^{4-}\right|^{3-}$ solution containing $0.1 \mathrm{M}$ $\mathrm{KCl}$, after polymerization to obtain the transducer films with (a) 0 , (b) 2.0 , (c) 3.0, (d) 5.0 , and (e) $7.5 \mu \mathrm{C}$. Scan rate, $50 \mathrm{mV} \mathrm{s}^{-1}$; frequency range, $0.01 \mathrm{~Hz}-10 \mathrm{kHz}$; excitation amplitude, $50 \mathrm{mV}$. Inset in Fig. $1 \mathrm{~B}$ is the equivalent circuit. $\mathrm{R}_{\mathrm{s}}=$ solution resistance, $\mathrm{CPE}=$ constant phase element, $\mathrm{R}_{\mathrm{ct}}=$ charge transfer resistance.
Au $\mu$ E/PEDOT(PSS) electrodes are much higher than that of the bare Au $\mu \mathrm{E}$. The equivalent circuit is shown in the inset of Fig. 1B. The diameter of the semicircle is directly related to the charge transfer resistance, $R_{\mathrm{ct}}$, and $R_{\mathrm{ct}}$ is inversely proportional to the polymerization charge [31,32]. The $R_{\mathrm{ct}}$ of the Au$\mu \mathrm{E} / \mathrm{PEDOT}(\mathrm{PSS})$ is much lower than that of the bare $\mathrm{Au} \mu \mathrm{E}$. The resistance remains almost constant when the polymerization charge is higher than $5.0 \mu \mathrm{C}$. In this case, the resistance of the Au $\mu \mathrm{E} / \mathrm{PEDOT}(\mathrm{PSS})$ was $2.4 \pm 0.3 \mathrm{M} \Omega$ with a deposition time of $100 \mathrm{~s}$. For a lower resistance and shorter deposition time, the polymerization charge of $5.0 \mu \mathrm{C}$ was selected for the electrodeposition.

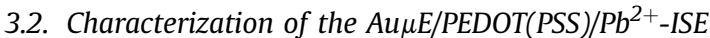

The selectivity coefficients of the $\mathrm{Pb}^{2+}$-ISM toward various interfering ions were examined by the separate solution method [33]. As shown in Fig. 2A, the results obtained are consistent with those of the $\mathrm{Pb}^{2+}$-ISE in the literature [34]. The selectivity coefficients toward sodium ions is $\log \mathbf{K}_{\mathbf{P b}, \mathbf{N a}}^{\mathbf{p o t}}=-7.6$, and a theoretical detection limit for lead ions in the presence of $0.5 \mathrm{M} \mathrm{Na}^{+}$can be
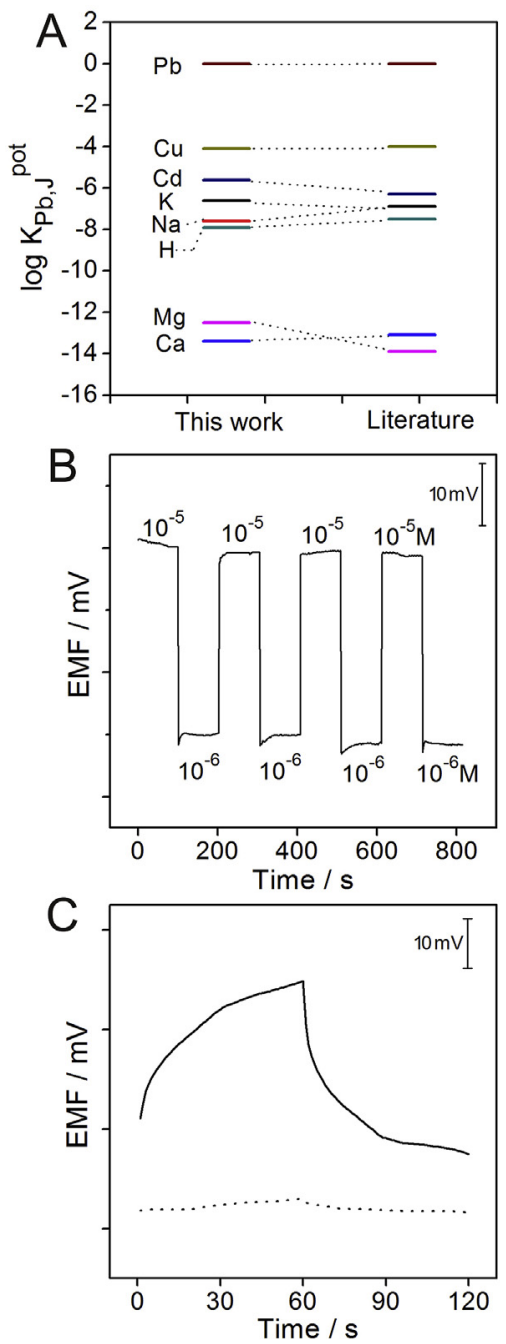

Fig. 2. (A) Comparison of the selectivity coefficients for the present $\mathrm{Pb}^{2+}$-ISM obtained with the separate solution method [33] and those reported in the literature [34]. (B) Potential reproducibility of the $\mathrm{Pb}^{2+}-\mathrm{IS} \mu \mathrm{E}$ evaluated by alternatively measuring $10^{-6} \mathrm{M}$ and $10^{-5} \mathrm{M} \mathrm{Pb}\left(\mathrm{NO}_{3}\right)_{2}(n=4)$. (C) Chronopotentiograms for the Au $\mu \mathrm{E} / \mathrm{Pb}^{2+}$-ISE (solid line) and $\mathrm{Au} \mu \mathrm{E} / \mathrm{PEDOT}(\mathrm{PSS}) / \mathrm{Pb}^{2+}$-ISE (dotted line) recorded in a $10^{-7} \mathrm{M} \mathrm{PbCl}_{2}$ solution in the background of $0.5 \mathrm{M} \mathrm{NaCl}$. The applied currents were $\pm 0.01 \mathrm{nA}$ for $60 \mathrm{~s}$. 
calculated to be $3.1 \times 10^{-9} \mathrm{M}$ [35]. According to the literature, the amount of dissolved lead in pore water ranges from micromole to nanomole $[4,36,37]$, therefore, the proposed $\mathrm{Pb}^{2+}-\mathrm{IS} \mu \mathrm{E}$ has a potential application in pore water measurement. Moreover, the $\mathrm{Pb}^{2+}$-ISM shows good selectivity coefficient toward $\mathrm{H}^{+}\left(\log \mathbf{K}_{\mathbf{P b} \mathbf{H}}^{\mathbf{p o t}}\right.$ $=-7.9$ ), which indicates that the $\mathrm{Pb}^{2+}$-ISM is insensitive to sample $\mathrm{pH}$.

The reproducibility of the $\mathrm{Pb}^{2+}-\mathrm{IS} \mu \mathrm{E}$ was investigated by alternatively measuring $10^{-6}$ and $10^{-5} \mathrm{M} \mathrm{Pb}\left(\mathrm{NO}_{3}\right)_{2}$ (Fig. 2B). The standard deviations of the potential values were calculated to be $\pm 0.84 \mathrm{mV}$ for $10^{-6} \mathrm{M} \mathrm{Pb}\left(\mathrm{NO}_{3}\right)_{2}$ and $\pm 0.82 \mathrm{mV}$ for $10^{-5} \mathrm{M} \mathrm{Pb}\left(\mathrm{NO}_{3}\right)_{2}$ $(n=4)$, respectively.

The short-term potential stabilities of the $\mathrm{Au} \mu \mathrm{E} / \mathrm{Pb}^{2+}$-ISE and AupE/PEDOT(PSS)/ $/ \mathrm{Pb}^{2+}$-ISE were evaluated by the current-reversal chronopotentiometry [38]. Fig. 2C shows the typical chronopotentiograms for both electrodes. The potential drift of the Au $\mu$ E/PEDOT(PSS) $/ \mathrm{Pb}^{2+}$-ISE calculated from the ratio $\Delta \mathrm{E} / \Delta \mathrm{t}$, is $36.0 \pm 9.7 \mu \mathrm{V} / \mathrm{s}$ for the current of $0.01 \mathrm{nA}$, which is much lower than that of the Au $\mu \mathrm{E} / \mathrm{Pb}^{2+}$-ISE $(448.0 \pm 118.9 \mu \mathrm{V} / \mathrm{s})$. Therefore, the potential stability of the $\mathrm{Pb}^{2+}-\mathrm{IS} \mu \mathrm{E}$ can be significantly improved by using the PEDOT(PSS) film as solid contact. The long-term response stability of the $\mathrm{Pb}^{2+}-\mathrm{IS} \mu \mathrm{E}$ was also investigated (Fig. S2). A slight change of the detection limit of the $\mathrm{Pb}^{2+}-\mathrm{IS} \mu \mathrm{E}$ was observed after $72 \mathrm{~h}$. Since the thickness of the polymeric membrane was only a few micrometers, the leaching of the membrane components such as the ionophore, borate and plasticizer to the sample solution would be much pronounced, which would make the response behaviors of the microelectrode deteriorated in a few days [39].

The potentiometric responses of the $\mathrm{Pb}^{2+}-\mathrm{IS} \mu \mathrm{E}$ were investigated in $\mathrm{Pb}\left(\mathrm{NO}_{3}\right)_{2}$ solutions. As shown in Fig. 3A-a, the microsensor shows a linear response in the concentration range of $1.0 \times 10^{-9}-1.0 \times 10^{-3} \mathrm{M}$ with a slope of $29.9 \pm 1.2 \mathrm{mV} /$ decade $(n=5$,
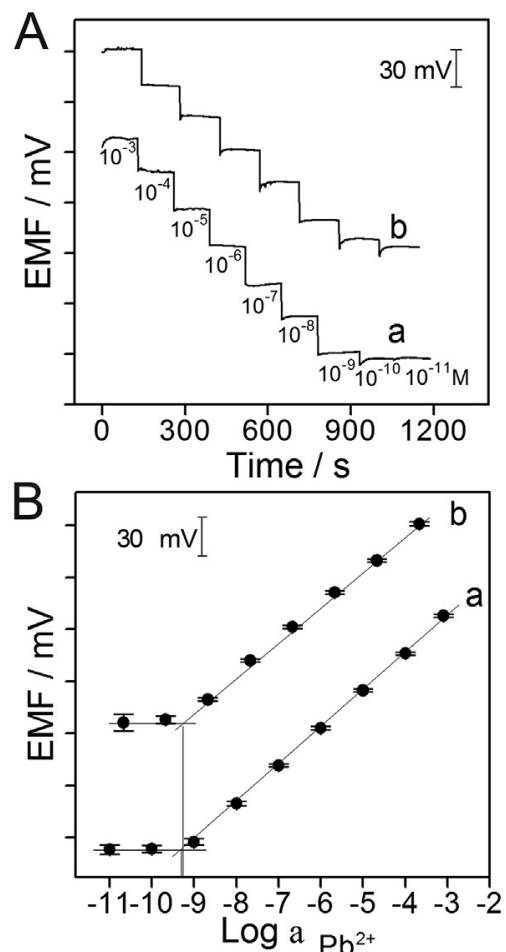

Fig. 3. (A) Potential response traces of the proposed $\mathrm{Pb}^{2+}-\mathrm{IS} \mu \mathrm{E}$ in $\mathrm{Pb}\left(\mathrm{NO}_{3}\right)_{2}$ at different concentrations in the absence (a) and presence (b) of $0.5 \mathrm{M} \mathrm{NaCl}$. (B) Calibration curves of the proposed $\mathrm{Pb}^{2+}-\mathrm{IS} \mu \mathrm{E}$ in $\mathrm{Pb}\left(\mathrm{NO}_{3}\right)_{2}$ in the absence (a) and presence (b) of $0.5 \mathrm{M}$ $\mathrm{NaCl}$.
$\left.\mathrm{R}^{2}=0.999\right)$, and the detection limit is $6.3 \times 10^{-10} \mathrm{M}($ Fig. $3 \mathrm{~B}-\mathrm{a})$. The $\mathrm{Pb}^{2+}$-IS $\mu \mathrm{E}$ can reach a low detection limit $\left(6.4 \times 10^{-10} \mathrm{M}\right)$ with the slope of $28.1 \pm 1.3 \mathrm{mV} / \mathrm{dec}\left(n=5, \mathrm{R}^{2}=0.998\right)$ even in the high electrolyte background of $0.5 \mathrm{M} \mathrm{NaCl}$ in the activity range of $2.1 \times 10^{-9}-2.1 \times 10^{-4} \mathrm{M}$ (Fig. 3A-b, Fig. 3B-b). This phenomenon may be ascribed to the more efficient ion diffusional transport due to the small size of microelectrode. The rapid diffusion process at the membrane/solution interface due to the small size of microelectrode could decrease the concentration of primary ions leaching from the membrane into the sample solution [40,41]. Therefore, the $\mathrm{Pb}^{2+}$-IS $\mu \mathrm{E}$ could be used for the in-situ measurement of $\mathrm{Pb}^{2+}$ in coastal sediments.

\subsection{Analytical applications}

The performance of the proposed $\mathrm{Pb}^{2+}-\mathrm{IS} \mu \mathrm{E}$ was first evaluated in the standard seawater sample before measuring the vertical profiles of free lead ions in the coastal sediment by the direct potentiometry. As shown in Figs. $4 \mathrm{~A}$ and $\mathrm{S} 3$, the $\mathrm{Pb}^{2+}-\mathrm{IS} \mu \mathrm{E}$ shows Nernstian response toward $\mathrm{Pb}^{2+}$ in the activity range of $2.0 \times 10^{-9}$ $2.0 \times 10^{-7} \mathrm{M}\left(\mathrm{S}=27.4 \pm 1.5 \mathrm{mV} / \mathrm{dec}, \mathrm{R}^{2}=0.999\right)$. Experiments were performed to determine if a stable response could be obtained when placing the $\mathrm{Pb}^{2+}-\mathrm{IS} \mu \mathrm{E}$ and reference electrode in direct contact with the sediment sample. Experiments revealed that the hydrophobic polymeric film was not altered when in contact with the sediment. Then, the proposed microsensor was used for the measurement of the vertical distribution of lead ions in coastal sediment pore water. The vertical distribution profile of lead ions within the upper $2 \mathrm{~cm}$ of the sediment core is shown in Fig. 4B, and the corresponding response traces are shown in Fig. S3. It can be seen that, the $\mathrm{Pb}^{2+}-\mathrm{IS} \mu \mathrm{E}$ allows measurements at a $2 \mathrm{~mm}$ spatial
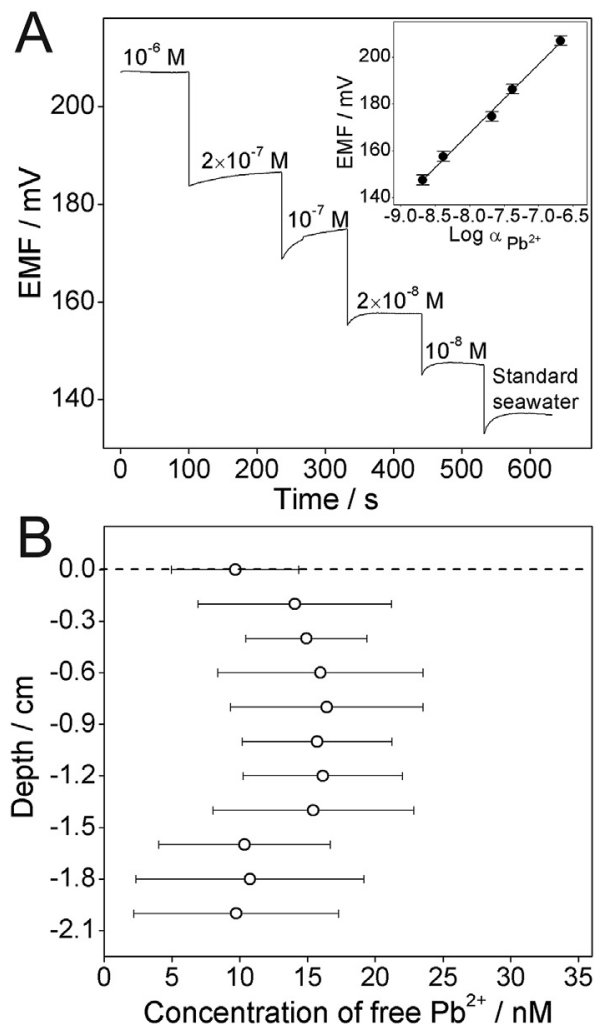

Fig. 4. (A) Potential responses of the $\mathrm{Pb}^{2+}-\mathrm{IS} \mu \mathrm{E}$ toward $\mathrm{Pb}^{2+}$ in the standard sea water. Inset shows the calibration curve of the electrode. (B) Profile of $\mathrm{Pb}^{2+}$ in the sediment pore water obtained by the proposed microsensor $(n=3)$. 
resolution. A peak concentration of $16.4 \mathrm{nM}$ was observed at the depth of $0.8 \mathrm{~cm}$, which indicates that there is considerable release of lead from the solid phase into the pore water. Due to the complicated chemical processes in surface sediments, the concentrations of dissolved heavy metals in pore water are related to various factors, such as dissolved oxygen [42], organic matters [36], and free sulphide [43]. For comparison, the pore water samples of the sediment core were also measured by anodic stripping voltammetry (ASV) via 797 VA computrace (Metrohm Ltd., Switzerland) [23]. The results obtained by these two methods were not consistent. For example, the concentration of $\mathrm{Pb}^{2+}$ at the depth of $0.5 \mathrm{~cm}$ measured by ASV was $27.4 \pm 1.0 \mathrm{nM}$, which is much higher than that obtained by the proposed microsensor $(16.0 \pm 7.9 \mathrm{nM})$. This phenomenon may be ascribed to the existence of large amounts of $\mathrm{CO}_{3}^{2-}$ in real samples, which could complex with free $\mathrm{Pb}^{2+}$ to form $\mathrm{PbCO}_{3}$. Indeed, $\mathrm{PbCO}_{3}$ cannot be detected by an ISE, but could be measured by ASV.

While the relative standard deviation of each series of three measurements was high, the in-situ measurement of $\mathrm{Pb}^{2+}$ through the proposed method allows rapid detection with high resolutions and could avoid problems of sample handling as compared to the DGT and stripping voltammetry methods [44,45]. The proposed allsolid-state IS $\mu \mathrm{E}$ shows high sensitivity and can be applied for in-situ measurement of $\mathrm{Pb}^{2+}, \mathrm{Ca}^{2+}, \mathrm{CO}_{3}^{2-}, \mathrm{pH}$ and so on in seawater sediments. The detection system could be coupled with other microsensors in the future work to obtain more information on heavy metals and related factors. It should be noted that the signals of the proposed $\mathrm{Pb}^{2+}$-IS $\mu \mathrm{E}$ became unstable at depths greater than $2 \mathrm{~cm}$. Therefore, the robustness of the proposed microsensor needs to be improved. Related works are in progress in this laboratory.

\section{Conclusions}

In this work, an all-solid-state $\mathrm{Pb}^{2+}$-IS $\mu \mathrm{E}$ using a PEDOT(PSS) film as solid contact has been developed, allowing real-time, highly spatial resolution measurements of the concentration profiles of free lead ions in coastal sediment pore water. The proposed microsensor exhibits excellent potentiometric characteristics in terms of low detection limit, and high selectivity. The microsensor was successfully applied for fine-scale in-situ measurements of $\mathrm{Pb}^{2+}$ in sediment pore water, which could capture high-resolution spatial concentration profiles of $\mathrm{Pb}^{2+}$.

\section{Declaration of interests}

The authors declare that they have no known competing financial interests or personal relationships that could have appeared to influence the work reported in this paper.

\section{Acknowledgements}

This work was financially supported by the National Natural Science Foundation of China (21677172, 41876108, and 21575158), the Instrument Developing Project of the Chinese Academy of Sciences (Y728021021), the National Key Research and Development Program of China (2016YFC1400700), and the Taishan Scholar Program of Shandong Province (TSPD20081215).

\section{Appendix A. Supplementary data}

Supplementary data to this article can be found online at https://doi.org/10.1016/j.aca.2019.04.059.

\section{References}

[1] C.W. Chen, C.M. Kao, C.F. Chen, C.D. Dong, Distribution and accumulation of heavy metals in the sediments of Kaohsiung Harbor, Taiwan, Chemosphere 66 (2007) 1431-1440.

[2] Z.Y. Chen, Y. Saito, Y. Kanai, T.Y. Wei, L.Q. Li, H.S. Yao, Z.H. Wang, Low concentration of heavy metals in the Yangtze estuarine sediments, China: a diluting setting, Estuar. Coast Shelf Sci. 60 (2004) 91-100.

[3] J.P. Shine, R. Ika, T.E. Ford, Relationship between oxygen consumption and sediment-water fluxes of heavy metals in coastal marine sediments, Environ. Sci. Technol. 17 (1998) 2325-2337.

[4] M.J. Ellwood, P. Wilson, K. Vopel, M. Green, Trace metal cycling in the Whau Estuary, Auckland, New Zealand, Environ. Chem. 5 (2008) 289-298.

[5] J.F. Peng, Y.H. Song, P. Yuan, X.Y. Cui, G.L. Qiu, The remediation of heavy metals contaminated sediment, J. Hazard Mater. 161 (2009) 633-640.

[6] S.E. Bufflap, H.E. Allen, Sediment pore water collection methods for trace metal analysis: a review, Water Res. 29 (1995) 165-177.

[7] S. Pradit, Y. Gao, A. Faiboon, S. De Galan, W. Baeyens, M. Leermakers, Application of DET (diffusive equilibrium in thin films) and DGT (diffusive gradients in thin films) techniques in the study of the mobility of sediment-bound metals in the outer section of Songkhla Lake, Southern Thailand, Environ. Monit. Assess. 185 (2013) 4207-4220.

[8] A.L. Fabricius, L. Duester, D. Ecker, T.A. Ternes, Metal and metalloid sizefractionation strategies in spatial high-resolution sediment pore water profiles, Environ. Sci. Technol. 50 (2016) 9506-9514.

[9] G.W. Luther, C.E. Reimers, D.B. Nuzzio, D. Lovalvo, In situ deployment of voltammetric, potentiometric, and amperometric microelectrodes from a ROV to determine dissolved $\mathrm{O}_{2}, \mathrm{Mn}, \mathrm{Fe}, \mathrm{S}(-2)$, and $\mathrm{pH}$ in porewaters, Environ. Sci. Technol. 33 (1999) 4352-4356.

[10] J. Pei, M.L. Tercier-Waeber, J. Buffle, Simultaneous determination and speciation of Zinc, Cadmium, Lead, and Copper in natural water with minimum handling and artifacts, by voltammetry on a gel-integrated microelectrode array, Anal. Chem. 72 (2000) 161-171.

[11] J. Pei, M.L. Tercier-Waeber, J. Buffle, G.C. Fiaccabrino, M. Koudelka-Hep, Individually addressable gel-integrated voltammetric microelectrode array for high-resolution measurement of concentration profiles at interfaces, Anal. Chem. 73 (2001) 2273-2281.

[12] J. Buffle, M.L. Tercier-Waeber, Voltammetric environmental trace-metal analysis and speciation: from laboratory to in situ measurements, Trac. Trends Anal. Chem. 24 (2005) 172-191.

[13] T. Sokalski, A. Ceresa, T. Zwickl, E. Pretsch, Large improvement of the lower detection limit of ion-selective polymer membrane electrodes, J. Am. Chem. Soc. 119 (1997) 11347-11348.

[14] E. Bakker, E. Pretsch, Nanoscale potentiometry, Trac. Trends Anal. Chem. 27 (2008) 612-618.

[15] J. Church, S.M. Armas, P.K. Patel, K. Chumbimuni-Torres, W.H. Lee, Development and characterization of needle-type ion-selective microsensors for in situ determination of foliar uptake of $\mathrm{Zn}^{2+}$ in citrus plants, Electroanalysis 29 (2017) $1-8$.

[16] D. Ammann, F. Lanter, R.A. Steiner, P. Schulthess, Y. Shijo, W. Simon, Neutral carrier based hydrogen ion selective microelectrode for extra- and intracellular studies, Anal. Chem. 53 (1981) 2267-2269.

[17] R.C. Thomas, W. Simon, M. Oehme, Lithium accumulation by snail neurones measured by a new $\mathrm{Li}^{+}$-sensitive microelectrode, Nature 258 (1975) 754-756.

[18] W.A. Timms, M.J. Hendry, Real-time analysis of small volume samples with micro ion-selective electrodes, Ground Water Monit. Rev. 24 (2004) 67-72.

[19] C.H. Han, W.J. Cai, Y. Wang, Y. Ye, Calibration and evaluation of a carbonate microsensor for studies of the marine inorganic carbon system, J. Oceanogr. 70 (2014) 425-433.

[20] B. Müller, K. Buis, R. Stierli, B. Wehrli, High spatial resolution measurements in lake sediments with PVC based liquid membrane ion-selective electrodes, Limnol. Oceanogr. 43 (1998) 1728-1733.

[21] P. Dauphin-Ducharme, R.M. Asmussen, D.W. Shoesmith, J. Mauzeroll, In-situ $\mathrm{Mg}^{2+}$ release monitored during magnesium alloy corrosion, J. Electroanal. Chem. 736 (2015) 61-68.

[22] T.J. Yin, D.W. Pan, W. Qin, All-solid-state polymeric membrane ion-selective miniaturized electrodes based on a nanoporous gold film as solid contact, Anal. Chem. 86 (2014) 11038-11044.

[23] G.T. Zhao, R.N. Liang, F.F. Wang, J.W. Ding, W. Qin, An all-solid-state potentiometric microelectrode for detection of copper in coastal sediment pore water, Sensor. Actuator. B Chem. 279 (2019) 369-373.

[24] R.E. Gyurcsányi, A.S. Nybäck, A. Ivaska, K. Tóth, G. Nagy, Novel polypyrrole based all-solid-state potassium-selective microelectrodes, Analyst 123 (1998) 1339-1344.

[25] J. Bobacka, Potential stability of all-solid-state ion-selective electrodes using conducting polymers as ion-to-electron transducers, Anal. Chem. 71 (1999) 4932-4937.

[26] U. Vanamo, E. Hupa, V. Yrjana, J. Bobacka, New signal readout principle for solid-contact ion-selective electrodes, Anal. Chem. 88 (2016) 4369-4374.

[27] T. Kitade, K. Kitamura, S. Takegami, Y. Miyata, M. Nagatomo, T. Sakaguchi, M. Furukawa, Needle-type ultra micro silver/silver chloride reference electrode for use in micro-electrochemistry, Anal. Sci. 21 (2005) 907-912.

[28] I. Uemasu, Y. Umezawa, Single ion activity at high ionic strengths with ionselective electrodes and the Debye-Hueckel equation, Anal. Chem. 55 (1983) 
386-388.

[29] A.J. Bard, L.R. Faulkner, Electrochemical Methods Fundamentals and Applications, second ed., John Wiley\&Sons, Inc., New York, 2001.

[30] J. Szücs, T. Lindfors, J. Bobacka, R.E. Gyurcsányi, Ion-selective electrodes with 3D nanostructured conducting polymer solid contact, Electroanalysis 28 (2016) 778-786.

[31] J. Duay, J.M. Goran, K.J. Stevenson, Facile fabrication of carbon ultramicro- to nanoelectrode arrays with tunable voltammetric response, Anal. Chem. 86 (2014) 11528-11532.

[32] A. Chen, D.J. La Russa, B. Miller, Effect of the iridium oxide thin film on the electrochemical activity of platinum nanoparticles, Langmuir 20 (2004) 9695-9702.

[33] E. Bakker, E. Pretsch, P. Bühlmann, Selectivity of potentiometric ion sensors, Anal. Chem. 72 (2000) 1127-1133.

[34] A. Ceresa, E. Pretsch, Determination of formal complex formation constants of various $\mathrm{Pb}^{2+}$ ionophores in the sensor membrane phase, Anal. Chim. Acta 395 (1999) 41-52.

[35] A. Ceresa, E. Bakker, B. Hattendorf, D. Günther, E. Pretsch, Potentiometric polymeric membrane electrodes for measurement of environmental samples at trace levels: new requirements for selectivities and measuring protocols, and comparison with ICPMS, Anal. Chem. 73 (2001) 343-351.

[36] A. Emili, A. Acquavita, S. Covelli, L. Spada, A. Di Leo, S. Giandomenico, N. Cardellicchio, Mobility of heavy metals from polluted sediments of a semienclosed basin: in situ benthic chamber experiments in Taranto's Mar Piccolo (Ionian Sea, Southern Italy), Environ. Sci. Pollut. Res. Int. 23 (2016) $12582-12595$.

[37] M.L. Tercier-Waeber, J. Pei, J. Buffle, G.C. Fiaccabrino, M. Koudelka-Hep, G. Riccardi, F. Confalonieri, A. Sina, F. Graziottin, A novel voltammetric probe with individually addressable gel-integrated microsensor arrays for real-time high spatial resolution concentration profile measurements, Electroanalysis 12 (2000) 27-34.
[38] J.H. Li, T.J. Yin, W. Qin, An all-solid-state polymeric membrane $\mathrm{Pb}^{2+}$-selective electrode with bimodal pore $\mathrm{C}_{60}$ as solid contact, Anal. Chim. Acta 876 (2015) 49-54.

[39] Y. Qin, S. Peper, A. Radu, A. Ceresa, E. Bakker, Plasticizer-free polymer containing a covalently immobilized $\mathrm{Ca}^{2+}$-selective ionophore for potentiometric and optical sensors, Anal. Chem. 75 (2003) 3038-3045.

[40] T. Sokalski, T. Zwickl, E. Bakker, E. Pretsch, Lowering the detection limit of solvent polymeric ion-selective electrodes. 1. modeling the influence of steady-state ion fluxes, Anal. Chem. 71 (1999) 1204-1209.

[41] R.J. Forster, Microelectrodes: new dimensions in electrochemistry, Chem. Soc. Rev. 23 (1994) 289-297.

[42] K.M. Xu, L.P. Zhang, W.B. Zou, Microelectrode study of oxygen uptake and organic matter decomposition in the sediments of Xiamen Western Bay, Estuar. Coasts 32 (2009) 425-435.

[43] S. Daniele, M.A. Baldo, C. Bragato, In situ monitoring of electroactive species by using voltammetry at microelectrodes, J. Braz. Chem. Soc. 13 (2002) 425-432.

[44] E.R. Unsworth, K.W. Warnken, H. Zhang, W. Davison, F. Black, J. Buffle, J. Cao, R. Cleven, J. Galceran, P. Gunkel, E. Kalis, D. Kistler, H.P. van Leeuwen, M. Martin, S. Noël, Y. Nur, N. Odzak, J. Puy, W, van Riemsdijk, L. Sigg, E. Temminghoff, M.-L. Tercier-Waeber, S. Toepperwien, R.M. Town, L. Weng, $\mathrm{H}$. Xue, Model predictions of metal speciation in freshwaters compared to measurements by in situ techniques, Environ. Sci. Technol. 40 (2006) 1942-1949.

[45] L. Sigg, F. Black, J. Buffle, J. Cao, R. Cleven, W. Davison, J. Galceran, P. Gunkel E. Kalis, D. Kistler, M. Martin, S. Noël, Y. Nur, N. Odzak, J. Puy, W. van Riemsdijk, E. Temminghoff, M.-L. Tercier-Waeber, S. Toepperwien, R.M. Town, E. Unsworth, K.W. Warnken, L. Weng, H. Xue, H. Zhang, Comparison of analytical techniques for dynamic trace metal speciation in natural freshwaters, Environ. Sci. Technol. 40 (2006) 1934-1941. 